\title{
Ferramentas 2.0 e bibliotecas universitárias brasileiras: Levantamento de uso e implicações
}

Pablo Diego Silva de Souza Jorge, Marcos Maurilio Ribeiro

\begin{abstract}
Resumo
Introdução: Apresenta o conceito de biblioteca 2.0, e como os serviços e produtos orientados nesta perspectiva transformariam as bibliotecas tradicionais em ambientes mais interativos e dinâmicos. Aborda como as ferramentas 2.0 - blogs, microblogs, redes sociais, wikis, portais de compartilhamento de imagens e vídeos, dentre outras - podem proporcionar o a primoramento dos processos de comunicação, transmissão da informação e aquisição do conhecimento, resultando em uma maior aproximação da biblioteca e do bibliotecário com os seus usuários. Método: Análise quantitativo-qualitativa de websites de bibliotecas de universidades públicas brasileiras (incluído o Distrito Federal) visando o levantamento do uso de ferramentas 2.0. Resultados: Observou-se que dezenove, da amostra de vinte e sete bibliotecas submetidas à análise utilizam alguma ferramenta 2.0. Verificou-se a preferência por três grupos de ferramentas 2.0 (Fontes RSS, Microblogs, e Redes Sociais). Verificou-se a não utilização de algumas ferramentas (Redes Sociais de Leitura, wikis, e Mensagens Instantâneas). Conclusões: As bibliotecas universitárias públicas brasileiras investigadas ainda têm uma modesta participação na esfera 2.0 o que dificulta o uso do potencial de comunicação, interação e colaboração destas ferramentas entre os usuários e usuários e bibliotecários.
\end{abstract}

\section{Palavras-chave}

Web 2.0. Bibliotecas e a Internet. Serviços de bibliotecas. Tecnologias sociais. Tecnologias da informação e comunicação.

\section{Introdução}

O desenvolvimento de novas tecnologias de informação e comunicação e a crescente utilização da Internet têm contribuído para uma reestruturação dos tradicionais processos de comunicação, transmissão da informação e aquisição do conhecimento.

Embora a tecnologia por si só não seja a resposta final para todos os problemas relacionados aos processos de comunicação, transmissão da informação e aquisição do conhecimento, ela conquista cada vez mais novos adeptos, sobretudo as tecnologias relacionadas à web 2.0. A web 2.0 é apresentada por O'Reilly (2005), como uma plataforma aberta e dinâmica, na qual há interação entre o produtor e o receptor da informação.

O termo web 2.0 foi promovido por Tim O’Reilly e Dale Dougherty em conferência realizada pela O'Reilly e a MediaLive International, em 2004, onde o termo foi primeiramente comunicado e conceitualizado como resultado de um brainstorming, no qual se discutia a ideia da web assumir características mais dinâmicas e interativas, de modo que os internautas pudessem colaborar com a criação de conteúdos (BLATTMANN; SILVA, 2007, p. 197).

É nesse contexto de interação, proporcionado pelas tecnologias relacionadas à web 2.0, que se iniciam os questionamentos sobre quais seriam as contribuições dessas novas tecnologias para bibliotecários e os seus usuários, especialmente ao que diz respeito aos produtos e serviços de informação oferecidos pelas bibliotecas.

Surge então o conceito de Biblioteca 2.0, como um ambiente de participação do usuário na criação e manutenção dos serviços, mantendo como objetivo principal a ampliação e o alcance da biblioteca para os usuários em potencial 
(CASEY; SAVASTINUK, 2007, p. 12). Tal conceito, assumido neste trabalho, sustenta a presente pesquisa que pretendeu investigar o uso efetivo, por bibliotecas universitárias brasileiras, de ferramentas/tecnologias 2.0 voltadas para a participação dinâmica nos processos de disseminação e compartilhamento de informação, aquisição de conhecimento e criação de novos conteúdos.

O conceito "biblioteca 2.0", em seu contexto baseado na abordagem centrada no usuário, permite - potencialmente - que as bibliotecas inovem e expandam de seus produtos e serviços, ganhando assim a possibilidade de atender um maior número de usuários simultaneamente (aprimorando a qualidade e rapidez de tais produtos e serviços). Além disto, a gratuidade de algumas das ferramentas derivadas, tais como blogs e wikis, são de conhecimento e uso pelos usuários em outros ambientes, facilitando a comunicação, a interação e a colaboração destes com a Biblioteca, como o que já ocorre em redes sociais, por exemplo.

A partir da revisão de literatura e análise de websites de bibliotecas de universidades públicas brasileiras, identificou-se o uso das ferramentas/tecnologias 2.0 como apoio aos serviços oferecidos pelas bibliotecas, discutindo-se esta utilização e a contribuição destas na inserção dos profissionais bibliotecários e das unidades de informação no novo contexto de comunicação, interação e colaboração proporcionado pela web 2.0.

\section{A evolução das bibliotecas e a biblioteca}

\section{0}

O conceito de biblioteca tradicional - aquela na qual informação e metainformação (isto é, seu acervo e a representação do mesmo) estão em formato impresso e disponível apenas para acesso local - representa basicamente a definição da palavra biblioteca vista como uma mera coleção de livros. Ou seja, a biblioteca como unidade física da forma que é conhecida tradicionalmente, com estantes e livros arranjados sistematicamente. Contudo, a biblioteca é também um "organismo vivo e em constante crescimento" (RANGANATHAN, 2009).

De acordo com Carrión Gútiez (2001), as bibliotecas têm evoluído de uma unidade física (lugar) para uma unidade lógica devido ao grau de impacto das novas tecnologias de comunicação e informação, o que alterou de forma significativa os métodos de elaboração de novos conteúdos informacionais, assim como os processos de organização, disseminação e acesso à informação. A biblioteca tradicional se desenvolveu, na primeira metade do século XX, primeiramente para a chamada biblioteca automatizada, quando se iniciaram os primeiros processos de automação, sobretudo nos Estados Unidos da América e, posteriormente, na Europa pós 2a Guerra Mundial. Uma das principais características da biblioteca automatizada é a introdução do computador, a existência de metadados digitais, bem como o surgimento dos catálogos públicos online.

A partir da biblioteca automatizada, já apoiada em aplicações online, avançou-se para o conceito da biblioteca híbrida, na qual coexistem as informações em formato impresso, magnético, ótico e digital, cujo o acesso, como aponta Carrión Gútiez (2001), pode ser tanto local como universal.

A biblioteca digital, na qual as informações e metainformações estão em formato digital (CARRIÓN GÚTIEZ, 2001), pode ser acessada remotamente, o que ampliou as possibilidades de acesso e uso do conteúdo informacional. Ainda assim, embora em meio digital, a biblioteca continua sendo a mesma, ou seja, usuários ainda não podem modificar e criar novos conteúdos.

Levando-se em consideração as evoluções sofridas ao longo da história e o novo contexto em que a sociedade se insere, tornou-se necessária a revisão do conceito de biblioteca. Maranhão (2011) relata a tendência do usuário em realizar pesquisas primeiramente em buscadores comerciais (como o Google) e não nos sites/portais das bibliotecas. Uma vez que Os catálogos online e as bibliotecas não são mais a primeira ferramenta ou o primeiro lugar que o 
pesquisador acessa ou procura para realizar sua pesquisa (MARANHÃO, 2011), um modelo contemporâneo de serviços sustentados pela o uso de ferramentas da web 2.0 poderia responder às mudanças constantes no comportamento $\mathrm{e}$ demandas dos usuários.

Neste contexto, a "Biblioteca 2.0" é uma comunidade virtual centrada no usuário, socialmente rica, e quase sempre é um espaço eletrônico igualitário (MANESS, 2007, p. 45). A atuação do profissional "Bibliotecário 2.0" se dá como um facilitador, provedor de suporte e não necessariamente o primeiro responsável pela criação do conteúdo. Esta concepção de biblioteca está centrada no usuário, com o objetivo de estimular o dinamismo e a interatividade dos indivíduos, e na qual se pode criar, localizar e compartilhar informações online. Nela, a tecnologia é instrumento essencial para viabilizar essa perspectiva (VIEIRA; CARVALHO; LAZZARIN, 2008).

Crawford (2006) apresenta sessenta e duas visões e sete definições do termo Biblioteca 2.0, apontando, adicionalmente, duas interpretações distintas ao o termo. A primeira interpretação, diz respeito a uma gama de novas e já conhecidas metodologias de aplicações e programas (software social, interatividade etc.), que podem ser úteis a muitas bibliotecas tanto no fornecimento de novos serviços, como em tornar disponíveis os serviços existentes em novas (e interessantes) formas. Inclui também um conjunto de conceitos sobre o serviços de bibliotecas.

A segunda interpretação confronta as vantagens indicadas, discutindo-se afirmações negativas sobre bibliotecas existentes nesta perspectiva, quanto a sua viabilidade, relevância e, especialmente, na ausência de mudanças para os usuários. Crawford (2006) explora profundamente a ambiguidade que cerca o termo, sugerindo que não há nada inerentemente novo sobre a ideia pautada nas tecnologias 2.0.

O termo "Biblioteca 2.0" segundo Habib (2006), foi introduzido por Michael Casey em setembro de 2005, em seu blog LibraryCrunch. O nasci- mento do termo e seu debate conceitual se deu na "biblioblogosfera" (blogs escritos e mantidos por bibliotecários ou instituições ligadas à biblioteconomia) e, em 2007, Maness (2007) definiu Biblioteca 2.0 como "a aplicação de interação, colaboração, e tecnologias multimídia baseadas em web para serviços e coleções de bibliotecas baseados em web", o autor sugere que esta definição seja adotada pela comunidade biblioteconômica (MANESS, 2007). De acordo com Maness (2007), uma teoria para biblioteca 2.0 se baseia em quatro elementos essenciais:

a) é centrada no usuário: usuários participam na criação de conteúdos e serviços. O consumo e a criação do conteúdo são dinâmicos e, consequentemente, as funções do bibliotecário e do usuário nem sempre são claras;

b) oferece uma experiência multimídia: ambos, coleções e serviços, contêm componentes de áudio e vídeo. Embora isso nem sempre seja citado como uma função de biblioteca 2.0, o autor considera necessária sua existência;

c) é socialmente rica: a presença da biblioteca na web interativa inclui a presença dos usuários. Existem tanto formas síncronas (ex.: mensagens instantâneas) e assíncronas (ex.: wikis) para os usuários se comunicarem entre si e com os bibliotecários;

d) é comunitariamente inovadora: este é talvez o aspecto mais importante e singular da biblioteca 2.0. Baseia-se no fundamento das bibliotecas como serviço comunitário, mas entende que as comunidades mudam, e as bibliotecas não devem apenas mudar com elas, mas permitir que os usuários mudem a biblioteca. Uma biblioteca 2.0 busca continuamente mudar seus serviços, criar novas formas de permitir que as comunidades, e não somente os indivíduos, busquem, encontrem e utilizem informação. 
Quanto aos elementos básicos da Biblioteca 2.0, Arnal (2007) lista os seguintes:

a) as atitudes do profissional da informação, tais como a melhora contínua, a confiança radical e o aproveitamento da inteligência coletiva;

b) as ferramentas, ou novas tecnologias da web 2.0, tais como blogs, wikis, RSS ${ }^{1}$, softwares sociais e mashups ${ }^{2}$;

c) o conteúdo social, ou seja, aquele construído pelos usuários, tais como comentários, $\operatorname{tags}^{3}$ e outras contribuições.

\section{Ferramentas 2.0: aplicabilidade em bibliotecas}

Existem ferramentas com tecnologia web 2.0 que estão presentes em diversos sites dinâmicos e que podem ser aplicadas em sites de bibliotecas, com o objetivo de inseri-las no contexto da web 2.0 (ou web social interativa).

A web 2.0 se apoia em ferramentas tecnológicas derivadas de diferentes aplicativos de programação. De acordo com Casey e Savastinuk (2007) as ferramentas podem ser agrupadas levando-se em consideração suas características em comum em: blogs, wikis, redes sociais, fontes RSS e mensagens instantâneas. Bradley (2007, apud WALIA; GUPTA, 2012) adiciona as categorias de portais de compartilhamento de favoritos, portais de compartilhamento de imagens, portais de compartilhamento de vídeos, e microblogs. Nesta e Mi (2011) ainda citam as redes sociais de leitura como um tipo de ferramentas da web 2.0. Para fins desta pesquisa, e considerando-se o entendimento da funcionalidade destas ferramentas nos serviços de bibliotecas, utilizaram-se as seguintes categorias:

a) blogs: ferramenta de publicação de conteúdos (posts ou entradas de texto) sobre um assunto em particular que combina texto, imagens e links para outros blogs, páginas da web e mídias relacionadas a seu tema. Possibilita que leitores deixem comentários de forma a interagir com o autor e outros leitores. Em bibliotecas essa ferramenta pode ser utilizada como meio de divulgação dos seus serviços (resumo de novas aquisições, sumário de periódicos correntes, tutoriais de treinamento, dentre outros) notícias de interesse geral e novidades. O blog oferece realimentação aos usuários que o acompanham. Exemplos de aplicativos: Wordpress, Blogger, BlogLines;

b) microblogs: permite que usuários enviem e recebam atualizações pessoais de outros contatos a partir de textos breves por meio do website do serviço ou por mensagens de texto (SMS). As atualizações são exibidas em tempo real no perfil de usuários. Segundo Milstein (2009), é um serviço do qual as bibliotecas (e bibliotecários) podem fazer bom uso sem gastar muito tempo ou esforço e que, normalmente, apresenta alto índice de adesão dos usuários. Exemplo de aplicativo: Twitter;

c) redes sociais: são sites de relacionamento social que permitem aos seus usuários compartilhar informações pessoais, trocar mensagens e participar de grupos de discussões com temas e interesses comuns, além de compartilhar conteúdos. Essa ferramenta permite às bibliotecas divulgar notícias de interesse geral e informações à comunidade de usuários. Exemplos de aplicativos: Facebook, LinkedIn;

d) redes sociais de leitura: voltadas para leitores de livros em geral. Permitem a catalogação, compartilhamento e recomendação de livros a uma rede de amigos. Possibilita a inclusão de tags e comentários (como resenhas) a livros, possibilitando a comunicação e intera-

\footnotetext{
${ }^{1}$ Really Simple Syndication.

${ }^{2}$ Conforme Maness (2007), mashups são aplicações ostensivamente híbridas, em que duas ou mais tecnologias ou serviços são combinados em outro elemento completamente novo.

${ }^{3}$ As tags ou etiquetas são termos simples para descrever recursos na web. (ARROYO VÁZQUEZ; MERLO VEGA, 2007).
} 
ção dos usuários. Nas bibliotecas, auxilia na divulgação dos livros disponíveis e auxilia no compartilhamento público de opiniões entre os usuários. Exemplos de aplicativos: LibraryThing, Skoob;

e) portais de compartilhamento de imagens: possibilitam a livre indexação/ classificação de assuntos das informações contidas em imagens pelo uso de tags (etiquetas) atribuídas livremente pelos usuários. Para as bibliotecas, a ferramenta permite que se disponibilizem e compartilhem fotos do seu espaço físico, assim como fotos de eventos, de campanhas, imagens de capas de livros, neste caso, em interação com o Online Public Access Catalog (OPAC). Exemplos de aplicativos: Flickr, Photobucket, ImageShack;

f) portais de compartilhamento de vídeos: permitem que os usuários carreguem e compartilhem vídeos em formato digital. Uma característica importante é que os vídeos compartilhados podem ser incluídos em blogs através de uma interface de programação de aplicativos Application Programming Interface (API), a qual facilita a troca de mensagens ou dados entre duas ou mais aplicações. A biblioteca pode criar e disponibilizar tutoriais de utilização do seu OPAC, vídeos educativos de preservação do acervo e divulgar eventos organizados internamente. Exemplos de aplicativos: YouTube, Vimeo, Dailymotion;

g) portais de compartilhamento de favoritos: caracterizados como serviços online que permitem adicionar, pesquisar e compartilhar websites favoritos (bookmarks) sobre qualquer assunto. É possível acrescentar título, tags e comentários referentes a cada bookmark, o que auxiliaria na divulgação de links interessantes e potencialmente úteis aos usuários. Exemplos de aplicativos: Delicious, Digg, StumbleUpon; h) wikis: ferramentas de criação de documentos online editáveis e colaborativos. Esses documentos podem abordar apenas um determinado assunto ou vários. A utilização dessa ferramenta em bibliotecas, possibilita, por exemplo, que um usuário compartilhe informações sobre determinado assunto específico de um livro que tenha lido, ou sobre outros. Exemplo de aplicativo: Wikipédia;

i) mensagens instantâneas (MIs): possibilitam a comunicação instantânea com contatos pré-cadastrados, prescindindo da instalação de software específico. Nas bibliotecas essa ferramenta pode expandir os serviços de referência tradicionais, possibilitar o atendimento a vários usuários de forma simultânea $\mathrm{e}$ independentemente da localização geográfica, desde que os usuários estejam conectados à rede mundial. Algumas redes sociais possuem sua própria ferramenta de MI. Exemplos de aplicativos: Google Talk, Live Messenger, Yahoo! Messenger, Skype;

j) fontes RSS (Feed): são listas de atualização de conteúdo de um determinado site, escritos com especificações baseadas em $\mathrm{XML}^{4}$. Um programa Leitor de Feed (agregador) permite que os usuários recebam atualizações do site de origem sem ter que visitá-lo. O ideal é que toda biblioteca possua uma ou mais fontes RSS em seu website relacionados a diversos temas de interesses dos usuários. Mais vantajoso ainda seria possuir fontes RSS personalizáveis voltadas para alcançar o maior número possível de usuários assinantes dos feed. Nesta categoria não se consideram os feed gerados por demais ferramentas 2.0, tais como os blogs e microblogs. Exemplos de aplicativos: Feed de Novas Aquisições, Feed de Notícias.

\footnotetext{
${ }^{4}$ XML é a sigla em inglês para eXtensible Markup Language, que, em português, significa linguagem extensível de marcação (SILVA, 2008).
} 


\section{Serviços de biblioteca 2.0: novas implicações, vantagens e desvantagens}

A Biblioteca 2.0 imbuída de uma "roupagem mais moderna" proveniente do uso de ferramentas 2.0, tenderá a transportar os serviços tradicionais para um novo patamar. Isto quer dizer que os serviços tradicionais presentes nas Bibliotecas 1.0, tais como o OPAC, alertas, sumários, dentre outros, não vão deixar de existir, mas serão inseridos no novo contexto de comunicação, interação e colaboração, baseados no conceito da abordagem centrada no usuário. Como comenta Maness (2007), a biblioteca tem tido presença na web por muitos anos e, com a Biblioteca 2.0 os usuários serão convidados a entrar em um ambiente que oferece, potencialmente, um pacote completo de serviços de biblioteca para o meio eletrônico.

A Biblioteca 2.0 pode oferecer aos seus usuários uma participação mais interativa, ou seja, colocar a inteligência coletiva a serviço de seu ambiente. Os serviços 2.0 deverão se concentrar na competência informacional de seus usuários e na simplificação da transferência da informação a partir do emprego de novos recursos. Por exemplo, os OPACs tradicionais podem dar lugar a OPACs sociais, em que os usuários poderão interagir, avaliando um documento ou a ele definindo tags relacionadas ao seu conteúdo (socialização da indexação). Serviços tradicionais de alertas ou de novas aquisições podem ser distribuídos através de um Feed RSS da biblioteca.

Levando-se em conta as ferramentas disponíveis e a filosofia social e interativa da Web 2.0 há, potencialmente, uma maior interação entre o usuário, a biblioteca e o bibliotecário uma vez que as atuais necessidades de informação dos usuários diferem das demandas anteriores ao advento das novas tecnologias de informação e comunicação.

A discussão apresentada anteriormente permite apresentar aspectos facilitadores (vantagens) a serem considerados por profissionais da informação quando da tomada de decisão no uso de serviços 2.0. Contudo, observam-se alguns fatores que dificultam a utilização desses serviços (desvantagens) ou até mesmo impedem que esses serviços sejam comuns no quadro de atividades das bibliotecas (Quadro 1).

Quadro 1 - Serviços de bibliotecas 2.0: vantagens e desvantagens

\begin{tabular}{|l|l|}
\hline \multicolumn{1}{|c|}{ Vantagens } & \multicolumn{1}{c|}{ Desvantagens } \\
\hline $\begin{array}{l}\text { acessibilidade - é necessário } \\
\text { apenas um computador } \\
\text { ou aparelho móvel (celular } \\
\text { smartphone) com acesso à rede } \\
\text { mundial }\end{array}$ & $\begin{array}{l}\text { dificuldade de acesso, } \\
\text { especialmente em conexões } \\
\text { lentas de internet }\end{array}$ \\
\hline $\begin{array}{l}\text { baixos custos - ferramentas } \\
\text { acessiveis e em grande parte } \\
\text { criadas em plataformas de } \\
\text { código livre e sem custo para } \\
\text { utilização }\end{array}$ & $\begin{array}{l}\text { prejuízos na autenticidade } \\
\text { e veracidade da informação } \\
\text { compartilhada, decorrentes } \\
\text { da participação coletiva na } \\
\text { elaboração de conteúdo }\end{array}$ \\
\hline $\begin{array}{l}\text { facilidade de implementação } \\
\text { e utilização devido à } \\
\text { constante atualização por seus } \\
\text { desenvolvedores que buscam } \\
\text { ampliar a base de usuários e a } \\
\text { usabilidade da ferramenta }\end{array}$ & $\begin{array}{l}\text { deficiência ou dificuldade na } \\
\text { moderação de comentários } \\
\text { e conteúdos enviados pelos } \\
\text { usuários }\end{array}$ \\
\hline $\begin{array}{l}\text { comunicação, interação e } \\
\text { participação efetiva dos } \\
\text { usuários }\end{array}$ & $\begin{array}{l}\text { segurança relativa, pois } \\
\text { hackers tenderão a testar a } \\
\text { vulnerabilidade dos sistemas }\end{array}$ \\
\hline $\begin{array}{l}\text { compartilhamento da } \\
\text { inteligência coletiva baseada na } \\
\text { co-criação de novos conteúdos }\end{array}$ & $\begin{array}{l}\text { desatualização das } \\
\text { informações e serviços } \\
\text { quando a comunidade } \\
\text { envolvida demonstra } \\
\text { dificuldade e desinteresse em } \\
\text { utilizar os serviços com base } \\
\text { em ferramentas 2.0 }\end{array}$ \\
\hline $\begin{array}{l}\text { facilidade de aceitação por } \\
\text { parte dos usuários, pois um } \\
\text { conjunto significativo de } \\
\text { usuários já utiliza ferramentas } \\
\text { 2.0 }\end{array}$ & $\begin{array}{l}\text { dificuldade de aceitação } \\
\text { por parte dos usuários, } \\
\text { especialmente aqueles com } \\
\text { baixo grau de inserção e } \\
\text { analfabetismo digital, ou } \\
\text { mesmo aqueles usuários } \\
\text { avessos à utilização de novas } \\
\text { tecnologias }\end{array}$ \\
\hline
\end{tabular}

Fonte: os autores.

Ainda assim, neste novo modelo apoiado em ferramentas 2.0 os serviços contam com a participação dos usuários que, juntamente com os bibliotecários, passam a criar novos conteúdos; A relação com o usuário se torna mais personalizada e estes são reconhecidos como colaboradores e não somente como meros consulentes de informações pré-formatadas. 


\section{Procedimentos metodológicos}

O presente estudo investigou quais ferramentas 2.0 são utilizadas por bibliotecas universitárias brasileiras e como se dá esta utilização.

O método utilizado para a realização do levantamento iniciou-se com a seleção das universidades públicas de cada Estado brasileiro (mais o Distrito Federal) que melhor se situam no Índice Geral de Cursos (IGC) $2011^{5}$, o qual é um indicador de qualidade de instituições de ensino superior.

O IGC é disponibilizado pelo Ministério da Educação (MEC) em seu website como arquivo Excel disponível para download. Nessa planilha, que informa a classificação de 226 instituições de ensino superior, foi possível aplicar um filtro por instituições públicas ou privadas, e classificar a instituições por ordem crescente ou decrescen-

Tabela 1 - Instituições selecionadas cuja respectiva biblioteca faz uso de ferramentas 2.0

\begin{tabular}{|c|c|c|}
\hline Instituição Pública de Ensino Superior & UF & $\begin{array}{l}\text { Presença de ferramenta } 2.0 \text { no site da } \\
\text { biblioteca }\end{array}$ \\
\hline Universidade Federal do Acre ............. & $\mathrm{AC}$ & Não \\
\hline Universidade Federal de Alagoas.... & $\mathrm{AL}$ & Sim \\
\hline Instituto Federal de Educação, Ciência e Tecnologia do Amazonas. & AM & Não \\
\hline Universidade Federal do Amapá... & $\mathrm{AP}$ & $\operatorname{Sim}$ \\
\hline Universidade Federal da Bahia...... & BA & $\operatorname{Sim}$ \\
\hline Universidade Federal do Ceará..... & $\mathrm{CE}$ & $\operatorname{Sim}$ \\
\hline Universidade de Brasilia .............. & DF & $\operatorname{Sim}$ \\
\hline Instituto Federal de Educação, Ciência e Tecnologia do Espírito Santo .... & ES & Não \\
\hline Universidade Federal de Goiás ......................... & GO & Sim \\
\hline Universidade Federal do Maranhão ................... & MA & Não \\
\hline Universidade Federal de Lavras........ & $M G$ & $\operatorname{Sim}$ \\
\hline Fundação Universidade Federal da Grande Dourados. & MS & Não \\
\hline Universidade Federal de Mato Grosso ........... & MT & Não \\
\hline Universidade Federal Rural da Amazônia....... & PA & $\operatorname{Sim}$ \\
\hline Universidade Federal de Campina Grande .. & $\mathrm{PB}$ & Sim \\
\hline Universidade Federal de Pernambuco .......... & $\mathrm{PE}$ & $\operatorname{Sim}$ \\
\hline Universidade Federal do Piauí...................... & $\mathrm{Pl}$ & $\operatorname{Sim}$ \\
\hline Universidade Estadual de Maringá ........ & $P R$ & Sim \\
\hline Universidade Estadual do Norte Fluminense Darcy Ribeiro.. & RJ & Não \\
\hline Universidade Federal do Rio Grande do Norte..... & RN & Sim \\
\hline Fundação Universidade Federal de Rondônia .... & RO & $\operatorname{Sim}$ \\
\hline Universidade Federal de Roraima ..... & $\mathrm{RR}$ & $\operatorname{Sim}$ \\
\hline Universidade Federal do Rio Grande do Sul ... & RS & $\operatorname{Sim}$ \\
\hline Universidade Federal de Santa Catarina ..... & $\mathrm{SC}$ & $\operatorname{Sim}$ \\
\hline Universidade Federal de Sergipe ................ & SE & $\operatorname{Sim}$ \\
\hline Fundação Universidade Federal do Abc ....... & $\mathrm{SP}$ & Sim \\
\hline Fundação Universidade Federal do Tocantins. . & TO & \\
\hline
\end{tabular}

Fonte: os autores.

${ }^{5}$ Elaborado pelo Ministério da Educação e atualizado em 15 de janeiro de 2013. Disponível em: <http://portal.inep.gov.br/indice-geralde-cursos>. 
te de IGC Faixa (um arredondamento do IGC Contínuo) e IGC Contínuo (número decimal que mostra a classificação recebida pelo MEC através de avaliação).

Compreendendo que cada universidade pode possuir vários campi, e que cada campus pode concentrar uma ou mais bibliotecas (central e setoriais), considerou-se apenas a biblioteca central/principal de cada instituição selecionada.

O website é a principal forma de divulgação das ferramentas 2.0. Através de busca no Google, obteve-se o endereço do respectivo website de cada universidade pública brasileira selecionada para o estudo. A partir de análise na estrutura do site das universidades, acessou-se o website de sua respectiva biblioteca. Caso a estrutura do site da universidade não apresentasse nenhum link referente à biblioteca central/principal, foi realizada busca no próprio site da instituição. A partir da identificação dos websites procedeu-se a análise de ocorrência de utilização de ferramentas 2.0.

\section{Resultados}

Analisando-se a página principal e as páginas de serviços oferecidos no website de cada biblioteca, identificou-se a presença ou não das ferramentas 2.0 (Tabela 1).

Das 27 bibliotecas de universidades públicas brasileiras, dezenove utilizam pelo menos uma ferramenta 2.0 (considerando-se as categorias assumidas para este trabalho). Vale ressaltar que, das oito bibliotecas que não utilizam ferramentas 2.0, cinco não tem website próprio.

Em seguida as instituições/bibliotecas foram redistribuídas por Região procedendo-se um levantamento do número de ocorrências de utilização de cada ferramenta (Tabela 2).

Observa-se que a região Centro-Oeste tem o menor percentual de bibliotecas que fazem uso de ferramentas 2.0. A Região Sul tem 100\% das bibliotecas com uso de alguma ferramenta 2.0. O Nordeste aparece em seguida com $89 \%$ de ocor-
Tabela 2 - Distribuição das bibliotecas de universidades públicas por Região e por indicativo de presença de ferramenta 2.0

\begin{tabular}{lccc}
\hline Região & Bibliotecas & $\begin{array}{c}\text { Ocorrências } \\
\text { de uso das } \\
\text { ferramentas }\end{array}$ & $\begin{array}{c}\text { Porcentagem } \\
\text { de } \\
\text { ocorrências }\end{array}$ \\
\hline Norte & 7 & 4.0 & $57 \%$ \\
Nordeste & 9 & 8 & $89 \%$ \\
Centro-Oeste & 4 & 2 & $50 \%$ \\
Sudeste & 4 & 2 & $50 \%$ \\
Sul & 3 & 3 & $100 \%$ \\
Totais & 27 & 19 & $70 \%$ \\
\hline
\end{tabular}

Fonte: os autores.

rência, considerando-se o total de bibliotecas na Região.

Avaliando-se o tipo de ferramenta, as Fontes RSS são as mais utilizadas, seguidas dos microblogs e das redes sociais $(52,63 \%$ das bibliotecas analisadas) (Tabela 3).

Conforme observado na análise dos websites das universidades em estudo, esses portais possuem embutidas em seu código fonte, ferramentas de Feed RSS, que são alimentadas automaticamen-

Tabela 3 - Utilização das ferramentas 2.0 nas bibliotecas de universidades públicas brasileiras

\begin{tabular}{|c|c|c|}
\hline Tipo de Ferramenta 2.0 & $\begin{array}{l}\text { Número de } \\
\text { ocorrências }\end{array}$ & Porcentagem \\
\hline 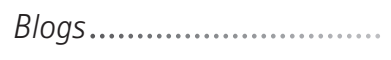 & 2 & $10,52 \%$ \\
\hline Microblogs ....................... & 10 & $52,63 \%$ \\
\hline Redes Sociais ..................... & 10 & $52,63 \%$ \\
\hline Redes Sociais de Leitura ..... & 0 & - \\
\hline $\begin{array}{l}\text { Portais de } \\
\text { Compartilhamento de }\end{array}$ & & \\
\hline Imagens....... & 1 & $5,26 \%$ \\
\hline $\begin{array}{l}\text { Portais de } \\
\text { Compartilhamento de }\end{array}$ & & \\
\hline Videos .......... & 2 & $10,52 \%$ \\
\hline $\begin{array}{l}\text { Portais de } \\
\text { Compartilhamento de }\end{array}$ & & \\
\hline Favoritos........................... & 1 & $5,26 \%$ \\
\hline Wikis.................. & 0 & - \\
\hline Fontes RSS (Feed) .............. & 13 & $68,42 \%$ \\
\hline Mensagens Instantâneas .... & 0 & - \\
\hline
\end{tabular}


te pelos administradores das páginas. Assim, se pode especular que a utilização mais frequente das fontes RSS nas bibliotecas se deve ao emprego de sistemas de gerenciamento de conteúdos de código aberto (como Plone, Drupal, dentre outros apresentados no Guia livre ${ }^{6}$ ) por parte das universidades públicas brasileiras. De acordo com o Programa de Governo Eletrônico Brasilei$\mathrm{ro}^{7}$, o software livre é uma opção estratégica do Governo Federal para reduzir custos, ampliar a concorrência, gerar empregos e desenvolver o conhecimento e a inteligência do país na área.

Juntamente com o Facebook, o mais expressivo representante das Redes Sociais, o microblog Twitter tem fácil aceitação por parte da maioria dos usuários das bibliotecas universitárias públicas brasileiras, o que justifica a posição de segundo lugar como ferramentas 2.0 de maior utilização. Segundo Chao (2013), as pessoas no Brasil estão gastando cada vez mais tempo conectados a sites de mídia social. Ainda de acordo com a autora, citando dados da comScore ${ }^{8}$, houve crescimento de $208 \%$ do tempo de utilização do Facebook e 41\% do Twitter, no país em 2012.

Outro ponto importante observado é a não utilização de ferramentas como as mensagens instantâneas (que podem ser utilizadas para serviços de referência online), as redes sociais de leitura e wikis. Os dados demonstram uma baixa utilização dos portais de compartilhamento de vídeos e de blogs.

\section{Considerações finais}

A Biblioteca 2.0 não tem como base o buscar, mas sim o encontrar; não prioriza o acesso, mas sim o compartilhamento (MANESS, 2007, p. 50). É um novo espaço de comunicação, interação e colaboração, um novo ambiente de aproveitamento da inteligência coletiva.
A biblioteca deve oferecer não somente os serviços pelos quais os usuários anseiam, mas deve ir além do que os usuários estão habituados. Ela deve ser pró-ativa, bem como deve apresentar, propor, formar, disponibilizar produtos e serviços que possam estar em conformidade com os novos meios de comunicação e informação, como as novas tecnologias.

Partindo da exposição de conceitos, definições e ideias a respeito da temática da Biblioteca 2.0, este trabalho apresentou uma breve descrição do funcionamento, da atuação e do uso por parte de bibliotecas de universidades públicas brasileiras de ferramentas 2.0 disponíveis.

Primeiramente, pode-se dizer que o termo Biblioteca 2.0, e mais diretamente a utilização das ferramentas 2.0, implica em um aumento da participação do usuário e do seu interesse no uso da biblioteca dentro do contexto de produção de conteúdo.

Contudo, a partir da descrição e análise dos dados obtidos no levantamento, as bibliotecas universitárias públicas brasileiras ainda têm uma modesta participação na esfera 2.0 , com utilização parcial das ferramentas disponíveis. Não foi objetivo deste trabalho, contudo, verificar as condições específicas de comunicação, interação e colaboração da web 2.0 existentes em tais bibliotecas, o que estimularia um segundo estudo qualitativo com seus gestores.

Espera-se que o número de bibliotecas das universidades públicas brasileiras que utilizem ferramentas 2.0 apresente um crescimento significativo nos próximos anos. Para tanto, os profissionais de informação, gestores de tais espaços, devem ser continuamente sensibilizados para as potencialidades das novas tecnologias de informação e comunicação.

\footnotetext{
${ }^{6}$ GUIA LIVRE. Referência de Migração para Software Livre do Governo Federal. Versão 1.0. Brasília, 2005. Disponível em: <http:// www.governoeletronico.gov.br/anexos/guia-livre-versao-1.0 >. Acesso em: 20 abr. 2013.

${ }^{7}$ PROGRAMA DE GOVERNO ELETRÔNICO BRASILEIRO. Software Livre. Disponível em: <http://www.governoeletronico.gov.br/ acoes-e-projetos/software-livre>. Acesso em: 4 maio 2013.

${ }^{8}$ COMSCORE. Empresa americana de análise de Internet. Disponível em: <http://www.comscore.com/>. Acesso em: 4 maio 2013 .
} 
Casey e Savastinuk (2007) recomendam que, embora a tecnologia seja um instrumento para melhor servir os usuários, ela não é a resposta final para todos os problemas apresentados por estes. As ferramentas tecnológicas aportarão importantes contribuições quando acompanhadas de uma mudança de atitude do profissional da informação, a qual deve voltar-se para a promoção da comunicação, interação e colaboração entre os usuários e o ambiente da biblioteca.

Para um melhor entendimento desta temática, sugere-se que futuros estudos abordem os aspectos das implicações causadas pela concretização do uso de ferramentas 2.0 nas bibliotecas universitárias públicas brasileiras, a partir da perspectiva dos usuários e, sobretudo dos bibliotecários.

\section{Referências}

ARNAL, D. M. Conceptos de Web 2.0 y biblioteca 2.0: origen, definiciones y retos para las bibliotecas actuales. El profesional de la información, v. 16, n. 2, p. 95-106, mar./abr. 2007. Disponível em: <http://www. elprofesionaldelainformacion.com/contenidos/2007/ marzo/02.pdf>. Acesso em: 4 maio 2013.

ARROYO VÁZQUEZ, N.; MERLO VEGA, J. A. La biblioteca como usuaria de La Web 2.0. In: JORNADAS ESPAÑOLAS DE DOCUMENTACIÓN, 10., 2007, Comunicaciones... Santiago de Compostela: FESABID, 2007. Disponível em: <http://www.fesabid. org/santiago2007/comunicaciones-relacion.php $>$. Acesso em: 4 maio 2013.

BLATTMANN, U.; SILVA, F. C. C. Colaboração e interação na Web 2.0. Revista ACB: Biblioteconomia em Santa Catarina, v.12, n.2, p. 191-215, jul./dez., 2007. Disponível em: <http://revista.acbsc.org.br/racb/ article/view/530>. Acesso em: 4 maio 2013.

CARRIÓN GÚTIEZ, A. Las tecnologías de la información y las comunicaciones en las bibliotecas públicas españolas: nuevos usuarios y nuevos servicios. In: FUNDACIÓN GERMÁN SANCHEZ RUIPÉREZ. Las bibliotecas públicas en España. Una realidad abierta. Madrid: Ministerio de Educación, Cultura y Deportes, 2001. Disponível em: <http://www.bibliotecaspublicas. info/bp/bp07_lamp.htm>. Acesso em: 4 maio 2013.

CASEY, M. E.; SAVASTINUK, L. C. Library 2.0: a guide to participatory Library service. Medford, NJ: Information Today, 2007.
CHAO, L. Brazil: the social media capital of the universe. The Wall Street Journal, Nova Iorque, 4 fev. 2013. Disponível em: <http://online.wsj.com/article/SB100 01424127887323301104578257950857891898.html >. Acesso em: 4 maio 2013.

CRAWFORD, W. Library 2.0 and "Library 2.0". Cites \& Insights, v. 6, n. 2, p. 1-32, 2006. Disponível em: <http://citesandinsights.info/l2a.pdf>. Acesso em: 4 maio 2013

HABIB, M. C. Toward Academic Library 2.0: development and application of a Library 2.0 methodology. Chapel Hill, North Carolina: University of North Carolina at Chapel Hill, 2006. Disponível em: <http://dc.lib.unc.edu/cdm/ref/collection/s_papers/ id/905>. Acesso em: 4 maio 2013.

MANESS, J. M. Teoria da Biblioteca 2.0: Web 2.0 e suas implicações para as bibliotecas. Informação \& Sociedade: Estudos, v. 17, n. 1, p. 43-51, jan./abr. 2007. Disponível em: <http://periodicos.ufpb.br/ojs2/ index.php/ies/article/view/831 >. Acesso em: 4 maio 2013. (Traduzido por Geysa Flávia Câmara de Lima Nascimento e Gustavo Henrique do Nascimento Neto).

MARANHÃO, A. M. N. Dos catálogos aos metabuscadores e serviços de descoberta na internet: uma visão geral. In: CONGRESSO BRASILEIRO DE BIBLIOTECONOMIA, DOCUMENTAÇÃO E CIÊNCIA DA INFORMAÇÃO, 24., 2011, Maceió, AL. Anais eletrônicos... Maceió: CBBD, 2011. Disponível em: <http://www.febab.org.br/congressos/index.php/ cbbd/xxiv/paper/view/312>. Acesso em: 4 maio 2013.

MILSTEIN, S. Twitter for Libraries (and Librarians). Computers in Libraries, v. 29, n. 5, Maio 2009. Disponível em: <http://www.infotoday.com/cilmag/ may09/Milstein.shtml>. Acesso em: 4 maio 2013.

NESTA, F; MI, J. Library 2.0 or Library III: returning to leadership. Library Management, v. 32, n. 1/2, p. 85-97, 2011. Disponível em: <http://dx.doi. org/10.1108/01435121111102601>. Acesso em: 4 maio 2013.

O'REILLY, T. What is Web 2.0? 30 set. 2005. Disponível em: <http://oreilly.com/web2/archive/what-is-web-20. html>. Acesso em: 4 maio 2013.

SILVA, M. S. Criando sites com HTML: sites de alta qualidade com HTML e CSS. São Paulo: Novatec, 2008.

RANGANATHAN, S. R. As cinco leis da biblioteconomia. Brasília, DF: Briquet de Lemos, 2009. 
VIEIRA, D. V.; CARVALHO, E. B. de; LAZZARIN, F. A. Uma proposta de modelo baseado na Web 2.0 para as bibliotecas das universidades federais. In: ENCONTRO NACIONAL DE PESQUISA EM CIÊNCIA DA INFORMAÇÃO, 9., 2008, São Paulo. Anais..., São Paulo: USP; ANCIB, 2008. Disponível em: <http://www.ancib.org.br/media/dissertacao/2053. pdf $>$. Acesso em: 4 maio 2013.

WALIA, P. K.; GUPTA, M. Application of Web 2.0 tools by national libraries. Webology, v. 9, n. 2, Dec. 2012. Disponível em: <http://www.webology.org/2012/v9n2/ a99.html>. Acesso em: 4 maio 2013.

\section{Internet 2.0 tools and Brazilian university libraries: Usage survey and its implications}

\section{Abstract}

Introduction: It introduces the concept of Library 2.0, and how services and products oriented in this perspective would transform traditional libraries into more interactive and dynamic environments. It shows how the tools 2.0 - blogs, microblogging, social networks, wikis, portals of sharing pictures and videos, among others - can provide an improvement of communication processes, information transmission and knowledge acquisition, bringing together the Library, the librarians and users. Method: A qualitative and quantitative analysis was performed at web sites of Brazilian public university libraries (including the Federal District) aiming to seek 2.0 tools usage. Results: It was found that nineteen libraries - of a sample of twenty seven - use at least one 2.0 tool. Three groups of 2.0 tools were found as being preferential (Sources RSS, Microblogs and Social Networks). Reading Social Network, wikis and instant messaging tools weren't found in any of the sites analyzed. Conclusions: Brazilian public university libraries still have a modest participation on the 2.0 sphere, which reduces the potential of communication, interaction and collaboration between users and librarians.

\section{Keywords}

Web 2.0. Libraries and the Internet. Library services. Social technologies. Information technology and communication.

Recebido em $1^{\circ}$ de abril de 2013

Aceito em 4 de maio de 2013

\section{Sobre os autores:}

\section{Pablo Diego Silva de Souza Jorge}

Bacharel em Biblioteconomia e Especialista em Arquitetura e Organização da Informação - Universidade Federal de Minas Gerais (UFMG). Bibliotecário - Conselho Regional de Odontologia de Minas Gerais (CROMG)

pablossj@gmail.com

\section{Marcos Maurilio Ribeiro}

Bacharel em Biblioteconomia - Universidade Federal de Minas Gerais (UFMG), Especialista em Biblioteconomia Faculdades Integradas de Jacarepaguá (FIJ/RJ). Bibliotecário - Universidade Federal de Itajubá (UNIFEI/Campus Itabira) marcosmribeiro@live.com

Como citar este artigo:

JORGE, P. D. S de S.; RIBEIRO, M. M. Ferramentas 2.0 e bibliotecas universitárias brasileiras: levantamento de uso e implicações. AtoZ: novas práticas em informação e conhecimento, Curitiba, v. 2, n. 1, p. 22-33, jan./jun. 2013. Disponivel em: <http://www.atoz.ufpr.br>. Acesso em: 
